\title{
Knowledge, Attitude and Practice of Malaysian Medical Doctors on Smoking Cessation Guidelines
}

Mohd Shaiful Ehsan Shalihin ${ }^{1}$, Mohamad Haniki Nik Mohamed ${ }^{2}$, Nurjasmine Aida Jamani $^{1}$, Mohd Aznan Bin Md Aris ${ }^{1}$

${ }^{1}$ Kulliyyah of Medicine, International Islamic University Malaysia

${ }^{2}$ Kulliyyah of Pharmacy, International Islamic University Malaysia

Introduction: Prevalence of active smokers in Malaysia is remaining high $(22.8 \%)$ despite the wide availability of quit-smoking services. Rather than look at the patients' factors alone, the possible negative factors from health care providers should also be explored. Therefore, knowledge, attitude and practice of the healthcare professional on smoking cessation intervention needs to be assessed, especially among the primary care doctors. This can be done during national conference gathering all doctors from Malaysia. Materials and Method: A crosssectional study was conducted among medical doctors attending First East Coast Symposium on Specialized Care at Primary Care Level at Grand DarulMakmur, Kuantan on $1^{\text {st }}$ to $2^{\text {nd }}$ December 2019, using validated questionnaire of Knowledge, Attitude and Practice of Medical Doctors on Smoking Cessation Guidelines; consisting 17 questions to determine the KAP score. The difference between the median KAP scores between age, gender, ethnicity, religion, profession, location of clinic, availability of specialist at clinic, numbers of smokers seen and presence of smoking cessation training were assessed using Independent sample T-test and One-way ANOVA. Results: A total of 131 primary care doctors involved in the study. Majority were female (80.9\%), Malay (96.2\%), medical officers $(74.8 \%)$, government doctors $(90 \%)$ and haven't undergone any kind of smoking cessation training $(65.5 \%)$. The higher KAP score were statistically associated $(p<0.05)$ with history of attending training program (mean 35.7 score) and in charge of quit smoking clinic (mean 35.4 score). No significant difference of score between government (mean 32.0 score) and private doctors (mean 29.9 score). Conclusions : Majority of the involved primary care doctors had low KAP score. Being a family medicine specialist, in charge in stop smoking clinic and have attended smoking cessation training program were significantly associated with high KAP score. Therefore, more smoking cessation training should be provided for doctors. 